\section{The Crystal Structure of $\mathrm{Ni}_{.55} \mathrm{Se}_{.08} \mathrm{Te}_{.37}$}

\section{KJELL HAUGSTEN and ERLING RøST}

Kjemisk Institutt, Universitetet i Oslo, Blindern, Oslo 3, Norway

A phase with composition $\mathrm{NiTe}_{0.7}$ and orthorhombic structure exists in the binary system nickel-tellurium. ${ }^{1}$ More than one half of the tellurium in this phase can be replaced by selenium, and for samples with a $\mathrm{Se} / \mathrm{Te}$ ratio greater than soout 0.22 the structure is hexagonal. ${ }^{2}$ The lattice constants vary continuously from $a=3.912, b=6.872$ and $c=12.37 \AA$ for $\mathrm{NiTe}_{0.77} 1$ to $a=3.735$ and $c=12.14 \AA$ for $\mathrm{Ni}_{.545} \mathrm{Se}_{.280} \mathrm{Te} .{ }_{.175}$, which is a sample near the selenium-rich limit of the phase." Density measurements showed that the unit cell contains eight chalcogen atoms in the orthorhombic and four in the hexagonal region, whereas a limited variation of the nickel content is possible. ${ }^{2}$

Single crystals were obtained by trans. port reactions at about $600^{\circ} \mathrm{C}$ with iodine as transporting agent. After fourteen days the dimension of the crystals was suitable for single crystal X-ray examination. Powder photographs of ground crystals indicate that the structure is hexagonal and the lattice constants are $a=3.836$ and $c=12.24$ A. On comparing this with the results of the previous investigation, ${ }^{2}$ the composition of the crystals was estimated to be about $\mathrm{Ni}_{.55} \mathrm{Se}_{.08} \mathrm{Te}_{.37}$. This is near the transition to orthorhombic structure.

A crystal $0.13 \mathrm{~mm}$ long with a cross section of 0.05 by $0.07 \mathrm{~mm}$ was used for Weissenberg photographs. MoK$\alpha$-radiation was used and Sn-foils were placed between the films. The crystal was rotated about the needle axis (a-axis) and intensity data from the layers $0 k l$ to $4 k l$ (orthorhombic indexing) were obtained. Corrections for absorption were made by assuming the crystal to be cylindrical. Hexagonal indexing gives 120 visible independent reflections. Systematically absent reflections are $l=2 n+1$ for $h-k=3 n$. This implies that all atoms are situated on threefold axis in the diagonal plane (110) referring to the trigonal or hexagonal space groups Nos. $159,163,173,176,182,186,190$, and $194 .^{3}$ Two different symmetries are possible. In the lower symmetry, represented by space groups Nos. 159, 173, and 186 the atoms are situated in the twofold positions, $\left(\frac{1}{3}, \frac{2}{3}, z\right.$; $\left.\frac{2}{3}, \frac{1}{3}, \frac{1}{2}+z\right)$, and $\left(0,0, z ; 0,0, \frac{1}{2}+z\right)$. The higher symmetry has an additional mirror plane at $z=\frac{1}{4}$ resulting in fourfold positions.

The structure was determined by threedimensional Patterson and Fourier synthesis, and by using a full matrix least squares program. ${ }^{4}$ As selenium and tellurium may be statistically distributed over the chalcogen positions, the atomic form factors used were interpolated by assuming $17.8 \%$ Se and $82.2 \%$ Te for the chalcogen according to the composition of the crystal. Refinements were carried out for both symmetries mentioned above. They lead to roughly the same crystal structure, and one cannot definitely decide which of them is the correct one in the present case.

In Table 1 are presented the results referring to the highest symmetry with a mirror plane at $z=1$. The corresponding reliability factor $\sum \| \boldsymbol{F}_{\mathrm{o}}|-| \boldsymbol{F}_{\mathrm{d}}|| / \sum\left|\boldsymbol{F}_{\mathrm{o}}\right|$ is 0.075 . The chalcogen positions are named (Se,Te) 1 and (Se,Te) 2 and the nickel positions Ni3 and Ni4. A projection of the hexagonal unit cell on the diagonal plane (110) is given in Fig. 1. Hatched circles represent atoms in the diagonal plane whereas the open circles represent atoms in the diagonal planes in the neighbouring unit cells. The distance between the planes is $\frac{1}{2} a(1.918 \AA)$.

Table 1. Positional parameters $(x, y, z)$, per cent occupancy, anisotropic temperature factors $B$, and root mean square amplitudes of vibration (in $\AA$ ). Estimated standard deviations are given in parenthesis.

\begin{tabular}{|c|c|c|c|c|c|c|c|c|}
\hline & $x$ & $y$ & $z$ & $\%$ occ. & $B_{11}$ & $B_{33}$ & $\begin{array}{c}\text { r.m.s. } \\
\left(u_{x}^{2}\right)^{2}\end{array}$ & $\begin{array}{l}\text { iplitude } \\
\left(u_{z}{ }^{2}\right)^{\frac{1}{z}}\end{array}$ \\
\hline$(\mathrm{Se}, \mathrm{Te}) 1$ in $(2 \mathrm{~b})$ & 0. & 0. & 0. & 100 & $0.078(4)$ & $0.0021(2)$ & 0.21 & 0.13 \\
\hline$(\mathrm{Se}, \mathrm{Te}) 2$ in $(2 \mathrm{c})$ & 0.3333 & 0.6667 & $0.2 \tilde{\xi}$ & 100 & $0.020(2)$ & $0.0036(2)$ & 0.11 & 0.17 \\
\hline $\mathrm{Ni3}$ in (4f) & 0.3333 & 0.6667 & $0.646(1)$ & 80 & $0.078(5)$ & $0.0026(4)$ & 0.21 & 0.14 \\
\hline $\mathrm{Ni4}$ in (4f) & 0.3333 & 0.6667 & $0.447(1)$ & 40 & $0.044(6)$ & $0.0016(5)$ & 0.16 & 0.11 \\
\hline
\end{tabular}

Acta Chem. Scand. 26 (1972) No. 1 
Table 2. Interatomic distances (in $\AA$ ) in $\mathrm{Ni}_{.55} \mathrm{Se}_{.08} \mathrm{Te}{ }_{.37}$. The number of equal distances is given in parenthesis.

\begin{tabular}{|c|c|c|c|c|c|c|c|}
\hline$(\mathrm{Se}, \mathrm{Te}) 1-$ & $\mathrm{Te}) 1$ & 3.84 & (4) & $(\mathrm{Se}, \mathrm{Te}) 2-($ & Te) 1 & 3.78 & (6) \\
\hline & $\mathrm{Te} 2$ & 3.78 & (6) & -1 & $\mathrm{Te}) 2$ & 3.84 & (4) \\
\hline - & $\mathrm{Ni3}$ & 2.85 & (6) & - & Ni3 & 2.55 & (6) \\
\hline - & $\mathrm{Ni4}$ & 2.31 & (6) & - & $\mathrm{Ni4}$ & 2.41 & (2) \\
\hline $\mathrm{Ni3}-$ & $\mathrm{Te}) 1$ & 2.85 & (3) & $\mathrm{Ni4}-($ & $\mathrm{Te}) 1$ & 2.31 & (3) \\
\hline & $\mathrm{Te} 2$ & 2.55 & (3) & -1 & $\mathrm{Te}) 2$ & 2.41 & (1) \\
\hline - & $\mathrm{Ni4}$ & 2.49 & (3) & - & $\mathrm{Ni} 3$ & 2.49 & (3) \\
\hline - & Ni4 & 2.44 & (I) & - & $\mathrm{Ni3}$ & 2.44 & (1) \\
\hline - & $\mathrm{Ni3}$ & 2.54 & (1) & - & $\mathrm{Ni4}$ & 2.57 & (3) \\
\hline
\end{tabular}

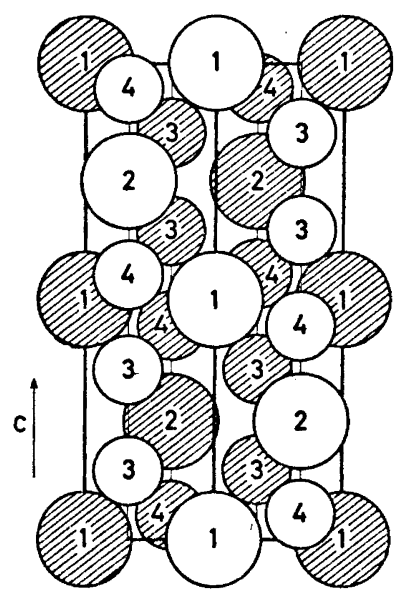

Fig. 1. A projection of $\mathrm{Ni}_{.55} \mathrm{Se}_{.08} \mathrm{Te}_{37}$ on the diagonal plane (110). The large and small circles represent $(\mathrm{Se}, \mathrm{Te})$ and $\mathrm{Ni}$ positions, respectively. Hatched circles represent atoms lying in the diagonal plane, and open circles atoms in positions $a / 2(1.918 \AA)$ above and below that plane. The lines parallel to the $c$ axis represent threefold axes.

The chalcogen atoms are stacked in a close-packed arrangement with layers in the sequence ABCABC..., whereas the nickel atoms are distributed in octahedral and tetrahedral holes in the chalcogen lattice. There is, however, no occupancy of the tetrahedral holes on the $z$-axes.

Interatomic distances are given in Table 2. The Ni3 atoms are octahedrally coordinated by chalcogen at distances of 2.55 and $2.85 \AA$ and further by five nickel atoms at distances from 2.44 to $2.54 \AA$. The Ni4 atoms are tetrahedrally coordinated by chalcogens at 2.31 and $2.41 \AA$ and further by seven nickel atoms at distances in the range 2.44 to $2.57 \AA$. The rather short distances $2.31 \AA$ between (Se, $\mathrm{Te}$ ) 1 and $\mathrm{Ni4}$ should be considered together with the reduced occupancy of the position Ni4. These short distances may also indicate that the selenium atoms are concentrated at the position (Se,Te)l rather than at $(\mathrm{Se}, \mathrm{Te}) 2$.

The tetrahedral sites on the $z$-axis might apparently contain $\mathrm{Ni}$ atoms. However, with the found atomic arrangement, the distances to the neighbouring nickel-atoms would be too short to be acceptable. Fourier synthesis and least squares refinements also showed that there is no occupancy of these positions.

Stevels ${ }^{4}$ has examined the structure of the binary phase $\mathrm{NiTe}_{0.77}$. He found an arrangement of tellurium atoms similar to that of the chalcogen atoms in the present structure. Detailed distribution of the nickel-atoms is not given, but the atomic arrangements of the orthorhombic phase are probably rather similar to that of the hexagonal region in the ternary system presented here.

The intensity data from the present in. vestigation can be obtained from the authors on request.

1. Barstad, J., Grønvold, F., Røst, E. and Vestersjø, E. Acta Chem. Scand. 20 (1966) 2865.

2. Røst, E. and Vestersjø, E. Acta Chem. Scand. 22 (1968) 2118.

3. International Tables for X-Ray Crystallography, Kynoch Press, Birmingham 1952.

4. Dahl, T., Gram, F., Groth, P., Klewe, B. and Rømming, Chr. Acta Chem. Scand. 24 (1970) 2232.

5. Stevels, A. L. N. Thesis, October 1969, Rijksuniversiteit, Te Groningen, The Netherlands.

Received December 10, 1971.

Acta Chem. Scand. 26 (1972) No. 1 